\title{
RELOCATION AND PREFERENTIAL ELUTION OF ACIDIC SOLUTE THROUGH THE SNOWPACK OF A SMALL, REMOTE, HIGH-ALTITUDE SCOTTISH CATCHMENT
}

\author{
by \\ P. Brimblecombe, M. Tranter, P.W. Abrahams, I. Blackwood, T.D. Davies and C.E. Vincent \\ (School of Environmental Sciences, University of East Anglia, Norwich NR4 7TJ, England)
}

\section{ABSTRACT}

This isolated snowpack shows wide spatial variability in composition, with 15 samples from a $700 \mathrm{~m}$ transect giving coefficients of variance of more than $50 \%$ for most of the major ions. Cations showed somewhat less variability than anions. Preferential elution, i.e. the more rapid loss of some ions from the pack than others, was more readily observed in the composition of meltwaters because of the high variability in snowpack composition. Preferential elution could be found in the snowpack where it was possible to resample a well-defined surface during a period of ablation. The elution sequence established from these surfaces was

$$
\mathrm{SO}_{4}^{2-}>\mathrm{NO}_{3}^{-}>\mathrm{NH}_{4}^{+}>\mathrm{K}^{+}>\mathrm{Ca}^{2+}>\mathrm{Mg}^{2+} \mathrm{H}^{+}>\mathrm{Na}^{+}>\mathrm{Cl}^{-}
$$

although the position of the hydrogen and ammonium ions may be affected by buffering. The sequence compares reasonably well with a generalized one assembled from earlier studies, where $\mathrm{SO}_{4}^{2-}$ is usually eluted quickly and sodium and chloride rather slowly. The evolution of the snowpack composition towards solute depletion, but relative richness in chloride, is clearly represented in triangular diagrams.

\section{INTRODUCTION}

For some time, it has been accepted that the fractionation of acidic solute into meltwater is responsible for the so-called acid flush, when between 50 and $80 \%$ of the total snowpack solute load is lost with the initial $20 \%$ of snowmelt (e.g. see Johannessen and Henriksen 1977, 1978, Cadle and others 1984). Recently, the fractionation of individual ions from a Norwegian firn core has been examined by Davies and others (1982). This work suggested that there was preferential elution of various solutes through snow and firn, and that sulphate, nitrate and possibly hydrogen ions were more rapidly eluted than the other major ions. Hence preferential elution of particular ions may enhance the fractionation of acidic solutes from snowpack into meltwater. Further work, focusing on both field and laboratory snowmelt experiments, has again demonstrated that acidic solutes in snow are not all lost at the same rate (Tsiouris and others 1985).

The effects of preferential elution can be most readily recognized in the composition of meltwaters. For example, Johannes and others (1981) found that the losses of sulphate, nitrate and hydrogen ions were from 66 to $83 \%$, 50 to $61 \%$ and 40 to $52 \%$ respectively in the initial 21 to $35 \%$ of water from a snow core, indicating that sulphate is preferentially eluted with respect to nitrate and hydrogen ions. In the past, the tendency has been to examine the fractionation of ions into meltwaters rather than the composition of a snowpack. The current work represents an attempt to find evidence for fractionation and preferential elution by examining the composition of a Scottish snowpack at various stages in its evolution over the late winter and spring of 1984 .

\section{METHODOLOGY}

Samples of snow were collected in the small (approximately $0.4 \mathrm{~km}^{2}$ ) catchment area of Ciste Mhearad
$(1080 \mathrm{~m})$, to the north-east of Cairn Gorm mountain, Scotland (lat $57^{\circ} 06^{\prime} \mathrm{N}$, long $03^{\circ} 38^{\prime} \mathrm{W}$ ) from January to May 1984. Parts of the catchment contain snow for much of the year, and it is remote from large sources of pollution (Davies and others 1984).

Snow samples were transferred into pre-washed polypropylene bottles with PTFE-coated plastic scoops. Surface snows were sampled to a depth of $2 \mathrm{~cm}$, and samples from within the snowpack were collected from the face of a snow-pit dug with a stainless-steel spade and faced by a plastic scoop. Snowmelt samples were collected from a ledge in the face of the snow-pit (see Tsiouris and others (1985) for fuller details). Fresh snowfall was collected whenever possible throughout the season, within $6 \mathrm{~h}$ of falling.

A series of snow-pits were sampled during late $(23$, $24,26)$ February. The first snow-pit was partially refilled after sampling, and sampling on successive days involved digging it out and refacing the sampling surface by at least $30 \mathrm{~cm}$. The same strata were resampled on each occasion after allowing for accumulation or ablation, which was estimated from the sampling locations of the previous day. A number of snow-pits at different locations were sampled periodically over the field season.

Transects along the axis of the catchment were made on four occasions, sampling surface snow at $50 \mathrm{~m}$ intervals. The A samples (sampled on 24 January 1984) demonstrated a variety of physical characteristics, from consolidated and coarse-grained snow to some surface ice, but, based on chemical composition, the surface consisted of only two snow types, which were easily separated by principal components analysis, or more crudely by $\mathrm{pH}$. The B samples (23 February 1984) represent acidic particulate-rich snow, containing flyash and carbonaceous material (Davies and others 1984), which had experienced melting and refreezing for 3 d. The physical state of the surface varied from little-altered snows to more consolidated snows with a thin ice covering.

The C samples (1 May 1984) represent a leached snow surface. During the preceding fortnight, the snowpack had been ablated by approximately $2 \mathrm{~m}$. The D samples ( 29 March 1984) represent a fresh surface covering of snowfall which fell a few hours before sampling. There had been little alteration of the fresh snow and the $\mathrm{pH}$ of the samples ranged from 3.50 to 3.65 .

The snow samples were transported to the field laboratory within a few hours of collection, still mainly in a frozen state, and were melted by immersing the bottles in hot water. The meltwater was immediately filtered through $0.45 \mu \mathrm{m}$ Oxoid filter membranes prior to the samples attaining room temperature $\left(8\right.$ to $12^{\circ} \mathrm{C}$ ), whereupon the $\mathrm{pH}$ was measured. Thereafter, they were stored at approximately $4{ }^{\circ} \mathrm{C}$ for up to three months.

The major metal ions $\left(\mathrm{Na}^{+}, \mathrm{K}^{+}, \mathrm{Mg}^{2+}, \mathrm{Ca}^{2+}\right)$ were determined by atomic absorption spectrophotometry on a Pye Unicam SP9 spectrophotometer, and the major anions ( $\mathrm{Cl}^{-}$, $\mathrm{NO}_{3}^{-}, \mathrm{SO}_{4}^{2-}$ ) were determined by ion chromatography on a Dionex Model 12 ion chromatograph. Precision of metal ion determinations was: $\mathrm{Na}^{+}{ }_{ \pm 0.04} \mathrm{ppm}$ and $\mathrm{K}^{+}, \mathrm{Mg}^{2+}$ and $\mathrm{Ca}^{2+}$ $\pm 0.01 \mathrm{ppm}$, and detection limits were an order of magnitude 
TABLE I. THE VARIATION OF MAJOR ION CONCENTRATIONS OF SURFACE SNOW SAMPLES COLLECTED ALONG TRANSECTS OF THE CATCHMENT

Aged snow cover*

A samples (24 January 1984) B samples (23 February 1984) C samples (1 May 1984)

\begin{tabular}{|c|c|c|c|c|c|c|c|c|c|c|c|c|}
\hline & $\min$ & $\max$ & mean & std & $\min$ & $\max$ & mean & std & $\min$ & $\max$ & mean & std \\
\hline $\mathrm{H}^{+}$ & 0.02 & 0.20 & 0.09 & 0.06 & 0.16 & 0.89 & 0.30 & 0.19 & 0.007 & 0.016 & 0.010 & 0.002 \\
\hline $\mathrm{Na}^{+}$ & 0.70 & 6.80 & 2.29 & 1.97 & 1.51 & 5.66 & 2.34 & 1.06 & 0.03 & 0.29 & 0.13 & 0.09 \\
\hline $\mathrm{K}^{+}$ & 0.02 & 0.37 & 0.14 & 0.11 & 0.06 & 0.29 & 0.10 & 0.06 & 0.002 & 0.024 & 0.012 & 0.006 \\
\hline $\mathrm{Mg}^{2+}$ & 0.07 & 0.84 & 0.28 & 0.25 & 0.20 & 0.73 & 0.28 & 0.14 & 0.002 & 0.007 & 0.004 & 0.002 \\
\hline $\mathrm{Ca}^{2+}$ & 0.05 & 0.29 & 0.12 & 0.08 & 0.12 & 0.41 & 0.27 & 0.09 & $* *$ & $* *$ & $* *$ & $* *$ \\
\hline $\mathrm{NO}_{3}^{-}$ & 0.42 & 2.68 & 1.12 & 0.72 & 4.05 & 13.4 & 6.23 & 2.55 & 0.033 & 0.126 & 0.063 & 0.024 \\
\hline $\mathrm{SO}_{4}^{2-}$ & 0.54 & 5.14 & 2.10 & 1.49 & 3.69 & 24.3 & 7.55 & 5.10 & 0.039 & 0.380 & 0.118 & 0.110 \\
\hline $\mathrm{Cl}^{-}$ & 1.42 & 16.2 & 5.21 & 4.72 & 3.85 & 7.42 & 5.45 & 1.02 & 0.22 & 0.86 & 0.48 & 0.21 \\
\hline $\begin{array}{l}\text { \%charge } \\
\text { balance } \\
\text { error }\end{array}$ & -12.5 & 33.1 & 6.96 & 11.8 & -6.30 & 17.0 & 1.93 & 6.93 & -29.6 & 25.7 & -0.86 & 15.2 \\
\hline
\end{tabular}

* units of concentration are ppm $\left(\mathrm{mg} \mathrm{l}^{-1}\right)$

** unavailable

TABLE II. THE CORRELATION COEFFICIENTS OF MAJOR IONS IN THE A, B AND C SAMPLES

A samples

\begin{tabular}{|c|c|c|c|c|c|c|c|c|}
\hline & $\mathrm{H}^{+}$ & $\mathrm{Na}^{+}$ & $\mathbf{K}^{+}$ & $\mathrm{Ca}^{2+}$ & $\mathrm{Mg}^{2+}$ & $\mathrm{NO}_{3}^{-}$ & $\mathrm{SO}_{4}^{2-}$ & $\mathrm{Cl}^{-}$ \\
\hline $\mathrm{H}^{+}$ & 1.000 & 0.098 & 0.058 & 0.259 & 0.143 & 0.903 & 0.624 & 0.095 \\
\hline $\mathrm{Na}^{+}$ & & 1.000 & 0.434 & 0.978 & 0.997 & 0.044 & 0.755 & 0.998 \\
\hline $\mathrm{K}^{+}$ & & & 1.000 & 0.441 & 0.443 & 0.029 & 0.299 & 0.429 \\
\hline $\mathrm{Ca}^{2+}$ & & & & 1.000 & 0.986 & 0.176 & 0.847 & 0.977 \\
\hline $\mathrm{Mg}^{2+}$ & & & & & 1.000 & 0.075 & 0.790 & 0.994 \\
\hline $\mathrm{NO}_{3}^{-}$ & & & & & & 1.000 & 0.517 & 0.059 \\
\hline $\mathrm{SO}_{4}^{z^{-}}$ & & & & & & & 1.000 & 0.753 \\
\hline $\mathrm{Cl}^{-4}$ & & & & & & & & 1.000 \\
\hline
\end{tabular}

B samples

\begin{tabular}{|c|c|c|c|c|c|c|c|c|}
\hline & $\mathrm{H}^{+}$ & $\mathrm{Na}^{+}$ & $\mathrm{K}^{+}$ & $\mathrm{Ca}^{2+}$ & $\mathrm{Mg}^{2+}$ & $\mathrm{NO}_{3}^{-}$ & $\mathrm{SO}_{4}^{2-}$ & $\mathrm{Cl}^{-}$ \\
\hline $\mathrm{H}^{+}$ & 1.000 & 0.919 & 0.951 & 0.300 & 0.948 & 0.962 & 0.977 & -0.071 \\
\hline $\mathrm{Na}^{+}$ & & 1.000 & 0.980 & 0.618 & 0.990 & 0.895 & 0.969 & 0.261 \\
\hline $\mathrm{K}^{+}$ & & & 1.000 & 0.517 & 0.994 & 0.911 & 0.985 & 0.097 \\
\hline $\mathrm{Ca}^{2+}$ & & & & 1.000 & 0.544 & 0.266 & 0.443 & 0.725 \\
\hline $\mathrm{Mg}^{2+}$ & & & & & 1.000 & 0.913 & 0.986 & 0.158 \\
\hline $\mathrm{NO}_{3}^{-}$ & & & & & & 1.000 & 0.943 & 0.050 \\
\hline $\mathrm{SO}_{4}^{2-}$ & & & & & & & 1.000 & 0.075 \\
\hline & & & & & & & & 1.000 \\
\hline
\end{tabular}

C samples

\begin{tabular}{|c|c|c|c|c|c|c|c|}
\hline & $\mathrm{H}^{+}$ & $\mathrm{Na}^{+}$ & $\mathrm{K}^{+}$ & $\mathrm{Mg}^{2+}$ & $\mathrm{NO}_{3}^{-}$ & $\mathrm{SO}_{4}^{2-}$ & $\mathrm{Cl}^{-}$ \\
\hline $\begin{array}{l}\mathrm{H}^{+} \\
\mathrm{Na}^{+} \\
\mathrm{K}^{+} \\
\mathrm{Mg}^{2+} \\
\mathrm{NO}_{3}^{-} \\
\mathrm{SO}_{4}^{2-} \\
\mathrm{Cl}^{-}\end{array}$ & 1.000 & $\begin{array}{l}0.302 \\
1.000\end{array}$ & $\begin{array}{l}0.249 \\
0.162 \\
1.000\end{array}$ & $\begin{array}{l}0.525 \\
0.301 \\
0.480 \\
1.000\end{array}$ & $\begin{array}{r}-0.187 \\
-0.244 \\
0.013 \\
0.160 \\
1.000\end{array}$ & $\begin{array}{r}0.065 \\
-0.464 \\
0.469 \\
0.011 \\
0.366 \\
1.000\end{array}$ & $\begin{array}{r}0.496 \\
0.849 \\
0.398 \\
0.464 \\
-0.065 \\
-0.126 \\
1.000\end{array}$ \\
\hline
\end{tabular}


less. Precision of anion determinations was better than $5 \%$, and detection limits were $\pm 0.01 \mathrm{ppm}$. An Orion 501 portable $\mathrm{pH}$ meter and Orion research grade $\mathrm{pH}$ electrode, calibrated with $\mathrm{BDH}$ buffers of 4.00 and 9.00 , were used to determine the activity of the hydrogen ion. Errors of at least $\pm 0.2 \mathrm{pH}$ units are likely because of the difficulties of the measurement of $\mathrm{pH}$ in solutions of low ionic strength (e.g. Galloway and others 1979, Neal and Thomas in press), although precision was $\pm 0.05 \mathrm{pH}$ units. A limited number of ammonia determinations were performed by AutoAnalyzer, using the indophenol blue method.

Charge balance errors were derived by dividing the difference between positive and negative equivalents by the total equivalents.

\section{RESULTS}

The chemical composition of the snowpack is highly variable. This can be seen from the variation of the surface composition along a $700 \mathrm{~m}$ transect of the catchment (see Table I). The coefficient of variance often exceeds $50 \%$ for many of the ions. However, each data set shows a high degree of internal consistency in that at least some of the major ions are well correlated (see Table II). Even the composition of a new snowfall shows wide compositional variations, with coefficients of variation around $40 \%$. Table III shows the variation of the $\mathrm{pH}$, and $\mathrm{NO}_{3}^{-}, \mathrm{SO}_{4}^{2-}$ and $\mathrm{Cl}^{-}$ concentrations of a newly fallen snow surface (D samples) along a transect of the catchment. Some of the inhomogeneity in the composition of fresh snowfall may arise from temporal and spatial variations in solute scavenging over the duration of the fall, possibly enhanced by aeolian movement of the fallen snow. Variations in the snowpack composition with time may be the result of preferential elution, lateral transport of meltwater and dry deposition onto the surface, processes which can operate on both local and more widespread scales.

TABLE III. THE VARIATION OF THE pH AND $\mathrm{NO}_{3}^{-}, \mathrm{SO}_{4}^{2-}$ AND $\mathrm{Cl}^{-}$CONCENTRATIONS ALONG A NEWLY FALLEN SNOW SURFACE (D SAMPLES)

\begin{tabular}{lccc}
$\mathrm{pH}$ & $\begin{array}{r}\mathrm{NO}_{3}^{-} \\
(\mathrm{ppm})\end{array}$ & $\begin{array}{c}\mathrm{SO}_{4}^{2-} \\
(\mathrm{ppm})\end{array}$ & $\begin{array}{c}\mathrm{Cl}^{-} \\
(\mathrm{ppm})\end{array}$ \\
\hline & & & \\
3.55 & 0.83 & 5.56 & 0.42 \\
3.50 & 1.50 & 5.79 & 0.63 \\
3.50 & 1.08 & 10.6 & 0.35 \\
3.60 & 0.98 & 3.70 & 0.25 \\
3.50 & 2.64 & 6.02 & 0.70 \\
3.50 & 2.34 & 5.79 & 0.84 \\
3.55 & 1.11 & 4.40 & 0.35 \\
3.55 & 2.34 & 5.09 & 0.49 \\
3.65 & 0.95 & 4.40 & 0.18 \\
3.60 & 1.36 & 4.63 & 0.46 \\
3.60 & 1.15 & 5.00 & 0.39 \\
3.60 & 1.01 & 4.17 & 0.28 \\
3.55 & 1.40 & 4.63 & 0.46 \\
3.50 & 2.05 & 5.56 & 0.67 \\
3.60 & 1.09 & 4.72 & 0.34
\end{tabular}

Samples were collected every $50 \mathrm{~m}$ along a $700 \mathrm{~m}$ transect of the catchment. The first sample is from the lowest sampling location, while the last sample is from the highest location. The difference in altitude between these locations is approximately $100 \mathrm{~m}$.

The variability of both fresh and aged snows is so large that it is difficult to show any statistically significant compositional differences between them. However, principal components analysis of the fresh and aged surface snows indicates that $96 \%$ of the total variance in the $\mathrm{H}^{+}, \mathrm{Mg}^{2+}$, $\mathrm{Na}^{+}, \mathrm{SO}_{4}^{2-}, \mathrm{NO}_{3}^{-}$and $\mathrm{Cl}^{-}$concentrations $\left(\mathrm{Ca}^{2+}\right.$ and $\mathrm{K}^{+}$have been ignored for simplicity) can be explained by two components (see Table IV). The first component seems to represent the overall effect of concentration, since all ions

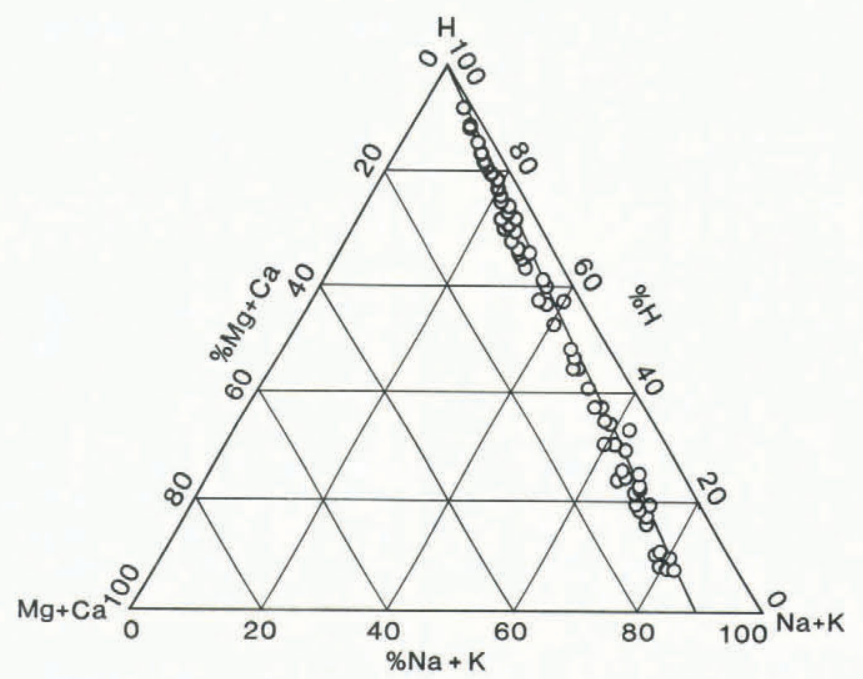

Fig.1. Triangular diagram of the cation composition of all snow samples collected, compared with the composition expected on the addition of acid to a sample with sea salt proportions of the major cations (shown by the solid line).

are equally loaded, and accounts for $72 \%$ of the total variance. The second component differentiates between sea salt $\left(\mathrm{Na}^{+}, \mathrm{Mg}^{2+}, \mathrm{Cl}^{-}\right)$and non-sea salt or acidic $\left(\mathrm{H}^{+}, \mathrm{SO}_{4}^{2-}\right.$, $\mathrm{NO}_{3}^{-}$) sources of solute and accounts for a further $24 \%$ of the variance. The mixing of an acidic component and a sea-salt component is shown in Figure 1, where cation compositions of all snows lie near to the theoretical mixing. The concentrations of $\mathrm{Ca}^{2+}$ and $\mathrm{K}^{+}$are small in comparison to the other cations, but calcium, derived from the dissolution of calcium sulphate on flyash particles (Raask 1981, Davies and others 1984) or other calcium-bearing minerals, shifts the intercept of the best fit straight line on the $\mathrm{Na}+\mathrm{K}, \mathrm{Ca}+\mathrm{Mg}$ axis to a ratio below that of sea-water. Principal components analysis does give some indication that less variability is to be found in the fresh snow. This is indicated in Figure 2 which plots the scores of the first and second principal components.

Because there is no simple method of distinguishing between fresh and aged snow, fractionation is more difficult to determine in snow profiles than in meltwaters, which

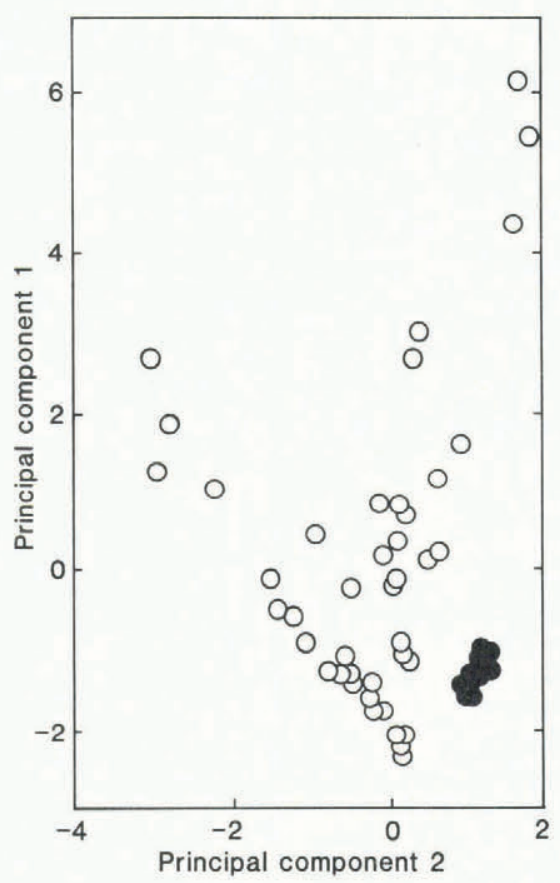

Fig.2. First and second principal component scores for sample sets A to D. The fresh snow is shown by the shaded dots. 
TABLE IV. THE PRINCIPAL COMPONENTS OF FRESH SNOWFALL AND THE AGED SNOW SURFACES

\begin{tabular}{lrrrrrrr} 
Variables & $\mathrm{Na}^{+}$ & $\mathrm{Mg}^{2+}$ & $\mathrm{H}^{+}$ & $\mathrm{SO}_{4}^{2-}$ & $\mathrm{NO}_{3}^{-}$ & $\mathrm{Cl}^{-}$ & $\begin{array}{l}\text { Cumuiative \% of } \\
\text { total variance }\end{array}$ \\
\hline Components & & & & & & & \\
$\quad \begin{array}{l}1 \\
2\end{array}$ & 0.412 & 0.408 & 0.381 & 0.412 & 0.421 & 0.415 & 71.8 \\
& -0.419 & -0.420 & 0.488 & 0.396 & 0.347 & -0.364 & 96.4
\end{tabular}

\begin{abstract}
Component 1 seems to represent the overall effect of concentration, since each ion is equally weighted, and accounts for $71.8 \%$ of the total variance of the ions.

Component 2 differentiates between the sea salt ions (which have negative weighting) and the acid ions, (which have positive weighting). This component accounts for a further $24.6 \%$ of the total
\end{abstract} variance.

represent homogenized samples from a considerable volume of snow. However it is important to be able to observe complementary behaviour between the composition of snow and meltwater as a snowpack melts, so that the effects of preferential elution can be established.

The determination of these effects within the snowpack requires the examination of the evolution of a well-defined snow mass of known composition with a high degree of confidence that variations observed are not due to lateral inhomogeneities. If it is assumed that the surface snows in the region of the series of snow-pits are chemically homogeneous and that inputs of dry deposition are small, preferential elution sequences can then be derived during a period of ablation. Over distances of $1 \mathrm{~m}$, where there are no surface irregularities, the assumption of surface chemical homogeneity is reasonable.

Table V lists the composition of the series of snow profiles during a period of ablation. The surface can be seen to become depleted in solute while there is simultaneous accumulation of solute further down the column. Accumulation appears to take place immediately above rather low permeability layers in the snowpack and the position of the accumulation zones varied on the latter $2 \mathrm{~d}$.

In this preliminary work, we will assume that preferential elution sequences are independent of concentration and the history of melting and refreezing. The sequence in which ions were eluted from the surface layer can be determined by comparing the ratio of each ion concentration in the initial surface to that found on resampling. Larger ratios indicate the more readily eluted ions. The following removal sequence is suggested from a comparison of the first (23 February 1984) and second (24 February 1984) surfaces:

$$
\mathrm{SO}_{4}^{2-}>\mathrm{NO}_{3}^{-}>\mathrm{NH}_{4}^{+}>\mathrm{K}^{+}>\mathrm{Ca}^{2+}>\mathrm{Mg}^{2+}>\mathrm{H}^{+}>\mathrm{Na}^{+}>\mathrm{Cl}^{-} .
$$

Small variations are obtained by comparing the first and third or second and third surfaces, and therefore this sequence is as yet only poorly defined. The sequence is similar to that derived by Tsiouris and others (1985) and is consistent with that derived from Johannes and others (1981). However, the position of the ammonium and hydrogen ions may be anomalous, since the ammonium ion may dissociate to buffer the loss of the hydrogen ions (i.e. $\mathrm{NH}_{4}^{+}=\mathrm{NH}_{3}+\mathrm{H}^{+}$), giving rise to higher ammonium and lower hydrogen ion mobilities.

Preferential elution sequences can be derived from previous snowmelt studies (Johannessen and Henriksen 1977, Johannessen and others 1977) by comparing the proportions of ions (relative to the bulk snow) lost with the first meltwater fractions. The sequences are listed in Table VI(a). Rank order analysis of these sequences, shown in the matrix in Table VI(b), suggests the elution sequence

$$
\mathrm{SO}_{4}^{2-}>\mathrm{Ca}^{2+}>\mathrm{Mg}^{2+}>\mathrm{H}^{+}>\mathrm{NH}_{4}^{+}>\mathrm{Cl}^{-}>\mathrm{NO}_{3}^{-}>\mathrm{Na}^{+}>\mathrm{K}^{+} .
$$

The present work suggests that potassium appears earlier in the sequence and that nitrate is more mobile than chloride. This was also found by Tsiouris and others (1985).

The elution sequences presented in Table $\mathrm{VI}(\mathrm{b})$ are statistically significant, as determined by the Kendall coefficient of concordance (see Seigel (1956) for a fuller account). The first sequence is significant at the $95 \%$ level $(\mathrm{N}=6, \mathrm{k}=8, \mathrm{~s}=332.8$, critical $\mathrm{s}(95 \%)=299.0$, where $\mathrm{N}$ is the number of variables and $\mathrm{k}$ is the number of ranks), while the second is significant at the $90 \%$ level $(\mathrm{N}=9, \mathrm{k}=5$, chi-squared $=14.3$, critical chi-squared $(90 \%)=13.4)$. However, until further work is done and the reproducibility of elution sequences is better known it is difficult to understand the different sequences in Table VI(a) or to reconcile sequences derived from the earlier literature with those determined in this work.

Since sulphate and nitrate are more mobile than chloride in the Scottish snowpack, the snow surface becomes relatively chloride-enhanced, even though there is net solute depletion. Since roughly similar proportions of cations are

TABLE V. THE COMPOSITIONAL VARIATIONS OF SURFACE AND WITHIN-COLUMN SNOW

\begin{tabular}{|c|c|c|c|c|c|c|c|c|c|c|}
\hline & $\begin{array}{l}\text { Date in } \\
\text { February } 1984\end{array}$ & $\mathrm{pH}$ & $\mathrm{Na}^{+}$ & $\mathrm{K}^{+}$ & $\mathrm{Mg}^{2+}$ & $\mathrm{Ca}^{2+}$ & $\mathrm{NO}_{3}^{-}$ & $\mathrm{SO}_{4}^{2-}$ & $\mathrm{Cl}^{-}$ & $\mathrm{NH}_{4}^{+}$ \\
\hline \multirow{3}{*}{$\begin{array}{l}\text { Surface snow } \\
0 \text { to } 5 \mathrm{~cm}\end{array}$} & 23 & 3.60 & 2.05 & 0.11 & 0.23 & 0.26 & 5.14 & 5.74 & 3.55 & 1.4 \\
\hline & 24 & 4.15 & 0.58 & 0.02 & 0.05 & 0.05 & 0.99 & 0.92 & 1.27 & 0.2 \\
\hline & 26 & 4.80 & 0.26 & 0.00 & 0.01 & 0.01 & 0.13 & 0.17 & 0.72 & $<0.1$ \\
\hline \multirow{3}{*}{$\begin{array}{l}\text { Snow at depth } \\
60 \text { to } 70 \mathrm{~cm}\end{array}$} & 23 & 4.80 & 1.64 & 0.04 & 0.18 & 0.07 & 0.08 & 0.55 & 4.52 & $<0.1$ \\
\hline & 24 & 4.10 & 4.72 & 0.12 & 0.55 & 0.24 & 1.38 & 3.31 & 8.50 & 0.2 \\
\hline & 26 & 4.55 & 2.73 & 0.06 & 0.30 & 0.12 & 0.30 & 1.19 & 6.20 & 1.7 \\
\hline \multirow{3}{*}{$\begin{array}{l}\text { Snow at depth } \\
115 \text { to } 125 \mathrm{~cm}\end{array}$} & 23 & 4.15 & 0.40 & 0.02 & 0.04 & 0.02 & 0.80 & 0.53 & 0.75 & 3.8 \\
\hline & 24 & 4.25 & 0.28 & 0.01 & 0.03 & 0.02 & 0.96 & 0.40 & 0.55 & 0.3 \\
\hline & 26 & 3.90 & 5.80 & 0.15 & 0.77 & 0.30 & 1.65 & 3.26 & 9.40 & 0.3 \\
\hline
\end{tabular}
DURING A PERIOD OF ABLATION (units of concentration are ppm $\left(\mathrm{mg}^{-1}\right)$ ) 
removed with the initial meltwater fractions when compared with later fractions, the anion compositional variations should be greater than those of the cations and should therefore provide a clear indication of the effects of preferential elution.

The composition of both snows and meltwaters evolve towards chloride-rich systems. This is demonstrated by the snow surfaces shown in Table $\mathrm{V}$ and the meltwater compositions shown in Table VII (for further examples, see Tsiouris and others (1985)), where only $7 \%$ of the variation in the anionic ratios can be attributed to analytical errors. A more immediate impression of evolution towards a chloride-rich system is obtained by plotting the anion data on a triangular diagram.

Acidic snows and meltwaters are particularly amenable

\section{TABLE VI(a). ELUTION SEQUENCES DERIVED FROM EARLIER WORK}

Elution sequence

Reference

$\mathrm{SO}_{4}^{2-}>\mathrm{Mg}^{2+}>\mathrm{NO}_{3}^{-}>\mathrm{Na}^{+}>\mathrm{Ca}^{2+}=\mathrm{H}^{+}$

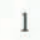

$\mathrm{Ca}^{2+}>\mathrm{H}^{+}>\mathrm{NO}_{3}^{-}>=\mathrm{NH}_{4}^{+}>\mathrm{Cl}^{-}=\mathrm{SO}_{4}^{2-}>\mathrm{Mg}^{2+}>\mathrm{Na}^{+} \quad 1$

$\mathrm{Ca}^{2+}>\mathrm{Mg}^{2+}>\mathrm{SO}_{4}^{2-}>\mathrm{H}^{+}=\mathrm{NO}_{3}^{-}>\mathrm{NH}_{4}^{+}>\mathrm{Cl}^{-}>\mathrm{Na}^{+}>\mathrm{K}^{+} \quad 1$

$\mathrm{SO}_{4}^{2-}>\mathrm{H}^{+}>\mathrm{Cl}^{-}>\mathrm{NH}_{4}^{+}>\mathrm{Mg}^{2+}>\mathrm{Na}^{+}>\mathrm{NO}_{3}^{-}>\mathrm{Ca}^{2+}>\mathrm{K}^{+} \quad 1$

$\mathrm{SO}_{4}^{2-}>\mathrm{Mg}^{2+}=\mathrm{K}^{+}>\mathrm{Ca}^{2+}>\mathrm{NH}_{4}^{+}>\mathrm{Na}^{+}>\mathrm{Cl}^{-}>\mathrm{NO}_{3}^{-}=\mathrm{H}^{+} \quad 1$

$\mathrm{Mg}^{2+}>\mathrm{SO}_{4}^{2-}>\mathrm{Ca}^{2+}>\mathrm{Na}^{+}>\mathrm{H}^{+}>\mathrm{NO}_{3}^{-}$

$\mathrm{Ca}^{2+}=\mathrm{Cl}^{-}>\mathrm{H}^{+}=\mathrm{NO}_{3}^{-}>\mathrm{Mg}^{2+}>\mathrm{SO}_{4}^{2-}>\mathrm{K}^{+}>\mathrm{Na}^{+}>\mathrm{NH}_{4}^{+} \quad 2$

$\mathrm{Ca}^{2+}>\mathrm{Mg}^{2+}>\mathrm{SO}_{4}^{2-}>\mathrm{H}^{+}>\mathrm{NO}_{3}^{-}>\mathrm{Cl}^{-}>\mathrm{Na}^{+}>\mathrm{NH}_{4}^{+}>\mathrm{K}^{+} \quad 2$

Reference 1: Johannessen and Hendriksen 1977.

Reference 2: Johannessen and others 1977. to representation on triangular diagrams since the bulk of the negative charge is carried by three anions: $\mathrm{SO}_{4}^{2-}, \mathrm{NO}_{3}^{-}$ and $\mathrm{Cl}^{-}$. Points which lie at the apices of the triangle represent meltwaters containing $100 \% \mathrm{SO}_{4}^{2-}, \mathrm{NO}_{3}^{-}$or $\mathrm{Cl}^{-}$, and points which lie closer to the chloride apex therefore contain proportionally more chloride. The triangular diagram has another important advantage; the effect of concentration, which accounts for $72 \%$ of the total variance of the chemical composition of surface snow, is eliminated and only proportions of the three components are considered.

Figure 3 shows all the (presently available) snow

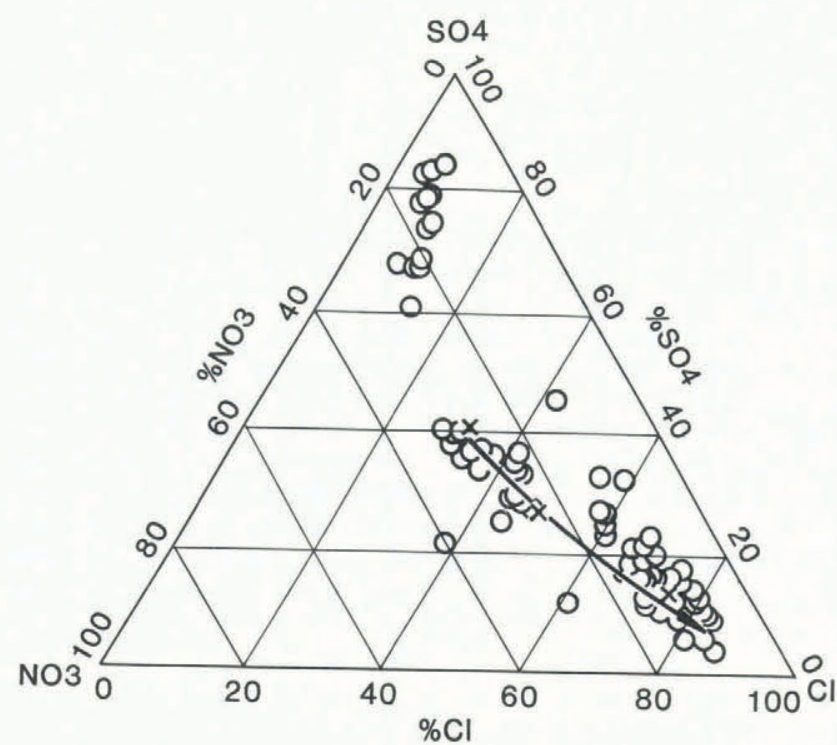

Fig.3. Triangular diagram of the molar fractional anion composition $\left(2 \mathrm{SO}_{4}+\mathrm{NO}_{3}+\mathrm{Cl}=1\right)$ of all presently-available snow samples. The arrow joins the three analyses of the well defined snow surface, showing its evolution to the chloride-rich apex under ablation conditions.

TABLE VI(b). MATRICES OF THE RANKINGS OF IONS IN THE SEQUENCES

SHOWN IN TABLE VI(a)

Matrix of rankings for ions in all sequences

\begin{tabular}{lllllll}
$\mathrm{SO}_{4}^{2-}$ & $\mathrm{Ca}^{2+}$ & $\mathrm{Mg}^{2+}$ & $\mathrm{H}^{+}$ & $\mathrm{NO}_{3}^{-}$ & $\mathrm{Na}^{+}$ \\
\hline
\end{tabular}

\begin{tabular}{|c|c|c|c|c|c|}
\hline 1 & 5 & 2 & 6 & 3 & 4 \\
\hline 4 & 1 & 5 & 2 & 3 & 6 \\
\hline 3 & 1 & 2 & 4 & 4 & 6 \\
\hline 1 & 6 & 3 & 2 & 5 & 4 \\
\hline 1 & 3 & 2 & 5 & 5 & 4 \\
\hline 2 & 3 & 1 & 5 & 6 & 4 \\
\hline 5 & 1 & 4 & 2 & 3 & 6 \\
\hline 3 & 1 & 2 & 4 & 5 & 6 \\
\hline 2 & 21 & 22 & 30 & 34 & 40 \\
\hline
\end{tabular}

\section{Matrix of rankings for sequences containing all ions}

\begin{tabular}{ccccccccc}
$\mathrm{SO}_{4}^{2-}$ & $\mathrm{Ca}^{2+}$ & $\mathrm{Mg}^{2+}$ & $\mathrm{H}^{+}$ & $\mathrm{NH}_{4}^{+}$ & $\mathrm{Cl}^{-}$ & $\mathrm{NO}_{3}^{-}$ & $\mathrm{Na}^{+}$ & $\mathrm{K}^{+}$ \\
\hline 3 & 1 & 2 & 4 & 6 & 7 & 4 & 8 & 9 \\
1 & 8 & 5 & 2 & 4 & 3 & 7 & 6 & 9 \\
1 & 4 & 2 & 8 & 5 & 7 & 8 & 6 & 2 \\
6 & 1 & 5 & 3 & 9 & 1 & 4 & 8 & 7 \\
3 & 1 & 2 & 4 & 8 & 6 & 5 & 7 & 9 \\
\hline
\end{tabular}

Sum 14

15

16

21

22

24

28

35 
TABLE VII. THE TEMPORAL VARIATION OF THE ANIONIC COMPOSITION OF MELTWATER SAMPLED ON 2 MAY 1984 (units are ppm)

\begin{tabular}{llllll} 
Time & $\mathrm{NO}_{3}^{-}$ & $\mathrm{SO}_{4}^{2-}$ & $\mathrm{Cl}^{-}$ & $\mathrm{Cl}^{-} / \mathrm{NO}_{3}^{-}$ & $\mathrm{Cl}^{-} / \mathrm{SO}_{4}^{2-}$ \\
\hline & & & & & \\
12.30 & 3.10 & 3.24 & 2.50 & 0.81 & 0.77 \\
13.00 & 3.49 & 3.93 & 2.17 & 0.62 & 0.55 \\
13.30 & 2.07 & 2.36 & 1.49 & 0.72 & 0.63 \\
14.00 & 1.52 & 1.63 & 1.23 & 0.81 & 0.75 \\
14.30 & 1.12 & 1.15 & 0.93 & 0.83 & 0.81 \\
15.00 & 1.08 & 1.08 & 0.89 & 0.82 & 0.87 \\
15.30 & 0.99 & 0.97 & 0.86 & 0.87 & 0.90 \\
16.00 & 0.93 & 0.91 & 0.82 & 0.88 & \\
\hline
\end{tabular}

samples analyzed over the current season plotted as a triangular diagram. Superimposed on the diagram are the three surface snows sampled over a period of ablation. The evolution of the snow surface towards the chloride apex is clearly seen. Much of the spread across the triangle between the chloride and sulphate apices is due to differences in the initial composition. In the case of Scottish snowfall, it may be imagined as the mixing of a sulphate-rich component by a sea salt-rich component. However evolution of snows also tends to follow the same trend, as indicated by the leached surface snows. Figure 4 compares newly fallen snows (which were the precursors of the three surface snows mentioned

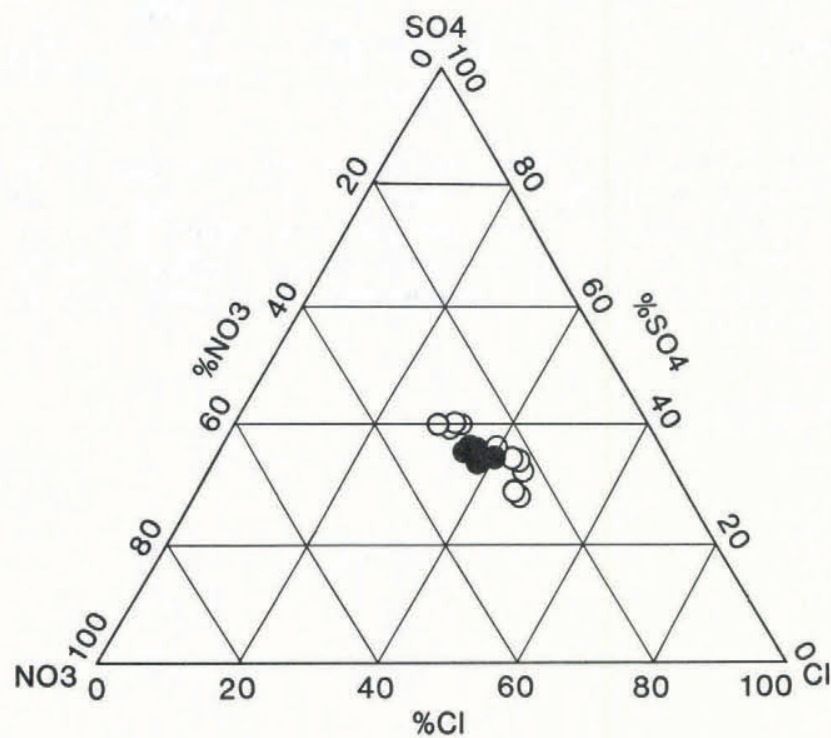

Fig.4. Triangular diagram of the anion composition of fresh snow (black dots) compared to the surface composition after $3 \mathrm{~d}$.

above), sampled on 20 February 1984, with the catchment surface sampled on 23 February 1984 after a period of only slight ablation. It is interesting to note that some of the snows appear to have lost sulphate and nitrate and have evolved towards the chloride apex, while others have evolved away from it, perhaps due to accumulation of small amounts of meltwater enriched in sulphate and nitrate. Unfortunately, scatter in the data prevents a more thorough analysis.

The evolution of meltwaters (presented in Table VII) is now clearly shown in Figure 5, where, apart from the first sample of meltwater, evolution is towards the chloride apex in this simple example. More data, in association with discharge measurements, is required for a more rigorous analysis of meltwater evolution.

\section{CONCLUSIONS}

The snowfalls in a remote Scottish catchment show large and as yet incompletely explained variations in major solute concentations. The ionic ratios show less variability. It

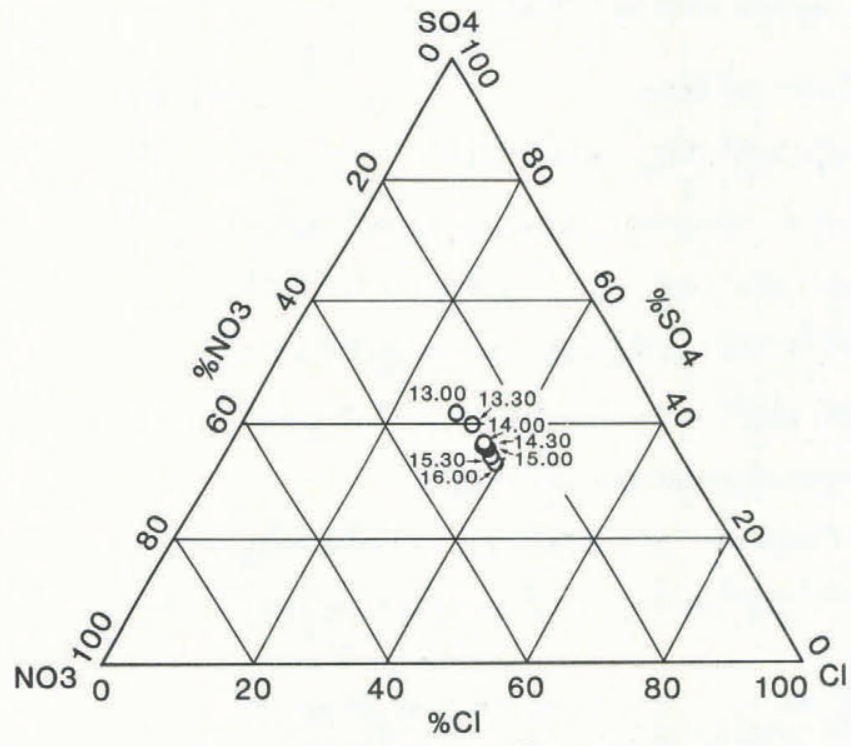

Fig.5. Triangular diagram of the anion composition of meltwaters collected on 2 May 1984.

is difficult to distinguish between fresh and weathered snow surfaces on the basis of chemical analysis alone.

Fractionation of the solute and preferential elution of specific ions into the earliest fractions of the meltwater is readily observed from meltwater analysis. It is much more difficult to detect these effects through analysis of individual samples from within a snow column. Inhomogeneities tend to obscure the transfer of solutes unless clearly defined snow volumes can be resampled for analysis. Where this is possible both fractionation and preferential elution are evident. In this preliminary work it has been assumed that preferential elution is independent of both concentration and the history of melting and refreezing.

Snows appear to become relatively chloride-rich as melting proceeds. There is a much smaller change in the nitrate:sulphate ratio, so that on a triangular diagram, evolution is towards the chloride apex. In the early stages of melting some snows may receive meltwater rich in sulphate and nitrate to become chloride-poor for a short time.

Anion ratios show more variation than cations. The alkali and alkaline earth cations seem to have fairly similar mobilities during melting. The mobilities of the ammonium ion and, more particularly, the hydrogen ion are more difficult to establish because of the possibility of equilibrium shifts.

\section{ACKNOWLEDGEMENTS}

The authors wish to thank $\mathrm{Dr}$ A G Thomas for performing the ammonia analyses. The research was funded by the Natural Environment Research Council and the European Commission. 


\section{REFERENCES}

Cadle S H, Dasch J M, Grossnickle N E 1984 Northern Michigan snowpack - a study of acid stability and release. Atmospheric Environment 18: 807-816

Davies T D, Vincent C E, Brimblecombe P 1982 Preferential elution of strong acids from a Norwegian ice cap. Nature 300(5883): 161-163

Davies T D, Abrahams P W, Tranter M, Blackwood I, Brimblecombe P, Vincent C E 1984 Black acidic snow in the remote Scottish Highlands. Nature 312(5989): 58-61

Galloway J N, Cosby B J, Likens G E 1979 Acid precipitation: measurement of $\mathrm{pH}$ and acidity. Limnology and Oceanography 24: 1161-1165

Johannes A H, Galloway J N, Troutman D E 1981 Snowpack storage and ion release. In Integrated Lake-Watershed Study, EPRI report, EA-125, 6-1

Johannessen M, Henriksen A 1977 Chemistry of snowmelt water: changes in concentration during melting. SNSF (Sur Nedbørs Virkning pả Skog og Fisk) Technical Report FR 11/77

Johannessen M, Henriksen A 1978 Chemistry of snow meltwater: changes in concentration during melting. Water Resources Research 14(4): 615-619

Johannessen M, Dale T, Gjessing E T, Henriksen A, Wright R F 1977 Acid precipitation in Norway: the regional distribution of contaminants in snow and the chemical concentration processes during snowmelt. Association of Hydrological Sciences Publication 118 (General Assembly of Grenoble 1976 - Isotopes and Impurities in Snow and Ice): 116-120

Neal $C$, Thomas A $G$ In press The measurement of $\mathrm{pH}$ in low conductivity waters: a case for the reappraisal of the techniques used. In Proceedings of Joint Meeting on Acid Rain. Institute of Water Pollution Control/Institute of Water Engineers and Scientists, 28 March 1984

Raask E 1981 Surface properties of pulverised coal ash and chimney solids. Power Industry Research 1: 233-251

Siegel S 1956 Nonparametric statistics. New York, McGraw-Hill

Tsiouris S, Vincent C E, Davies T D, Brimblecombe P 1985 The elution of ions through field and laboratory snowpacks. Annals of Glaciology 7: 196-201 